\title{
Operational and Environmental Impact of Ashes Produced from Combustion of Vineyard Wastes and their Blends in Fixed and Fluidized Bed Units
}

\author{
D Vamvuka*, A Stratakis and G Alevizos \\ Department of Mineral Resources Engineering, Greece
}

*Corresponding author: D Vamvuka, Department of Mineral Resources Engineering, Greece.

Received Date: December 12, 2018

Published Date: January 28, 2019

\begin{abstract}
The study aimed to provide valuable information for the promotion of vine by-products in fuelling small-to-medium size enterprises near wine/spirit processing industries. The objective was to evaluate and compare the ashes produced from both fixed and fluidized bed combustion of these wastes and their mixtures. Ashes were characterized by mineralogical, chemical, thermal and fusibility analyses and water leaching tests were conducted to remove problematic elements. Slagging/fouling propensities of ashes were determined, and their environmental impact and potential uses were assessed.

The results showed that all ashes were rich in $\mathrm{Ca}, \mathrm{K}, \mathrm{P}$ and Si incorporated mainly in calcite, fairchildite, hydroxyapatite and albite minerals. The fly ash of grape skins was enriched in K and P. Heavy metals showed less preference for fly ashes and all values were below the upper limit for disposal in landfills. The slagging/fouling tendency of grape skins ash was significant; however, no deposition is expected in systems operating below $100{ }^{\circ} \mathrm{C}$ for both fuels and their blend. Water leaching greatly reduced the slagging/fouling potential of ashes. Fixed bed or fly ashes could be used as secondary building materials or for road construction. Those of grape skins could also be used for soil amendment.
\end{abstract}

Keywords: Ashes; Vineyard wastes; Fixed bed; Fluidized bed

\section{Introduction}

Market needs for fuel diversification, as a result of high degree of dependence from fossil fuel imports and price fluctuations, in addition to policies of European Union and most countries across the world for reduction of greenhouse emissions and financial incentives, demand an increased share of biomass fuels in the heating and electricity sector [1].

In Northern European countries forestry residues are readily available in large quantities and are already used for power production. However, in South European countries agricultural and agro-industrial residues are the feedstocks of choice. In Greece, about 3.8 million dry tons of agricultural wastes are annually reduced [2]. In Crete, the largest Hellenic island, every year about 190800 tons of vine by-products with an energy potential of 3.6 $\mathrm{PJ} / \mathrm{y}$ remain practically unexploited [3]. Due to tourism industry, the energy demand in the island is very high, creating problems in the power supply. Thus, the thermal treatment of these wastes for energy recovery and increase of economic returns to rural communities seems a highly promising solution.

Biomass combustion systems are distinguished in fixed bed appliances, including grate furnaces and stokers and in fluidized bed appliances, operating in a bubbling or circulating mode. Fixed bed units usually present lower investment and operating costs for small-scale heat and power systems. On the other hand, fluidized bed units present inherent advantages, such as fuel flexibility, relatively low and uniform temperature, high efficiency and low emissions [4-6]. Despite their advantages, all these systems produce ash-forming species concentrated either in the bottom of the facilities or released as fly ashes and flue dust. These species, depending on their physical and chemical characteristics, boiler design and combustion conditions, may create technical and environmental problems, reducing the efficiency and availability of the plants, thereby increasing the power cost. Agglomeration, slagging, fouling and corrosion of surfaces are technical problems 
mainly arising from the presence of alkali metals, silicon, chlorine and sulphur in the ashes [7-9].

Contamination of air, soil and ground water, mainly arising from the presence of chlorine, sulphur and heavy toxic metals in ashes during combustion of fuels or disposal of ashes, are serious environmental problems threatening plants, animals and humans $[7,10]$. Nevertheless, some mineral nutrients in ashes, such as $\mathrm{Ca}$, $\mathrm{Mg}, \mathrm{N}, \mathrm{K}, \mathrm{P}$ and trace elements may have a vitalizing effect upon recycling to agricultural or forest soils [11]. Therefore, for the energy generation industry the successful operation of combustion systems, as well as the protection of the environment, are of great concern and depend on the ability to control ash operational problems, or the rational management of ashes, including their recycling and utilization in various applications.

There is a lot of information in literature on the characterization of bottom or fly ashes from combustion of woody materials [8,12$14]$ on the sintering mechanisms $[15,16]$, the leaching of various elements into soil $[17,18]$ and on possible uses for soil amendment or construction materials $[19,20]$. However, the need to introduce new biomass fuels into the market demands the use of feedstock blends in order to increase supply options. Vineyard by-products, although abundant in Mediterranean countries are not yet used for heat or power production. There is lack of data (excluding the author) on combustion efficiency and emissions of raw vineyard wastes and even more of mixtures of them $[6,21]$, the compatibility of which has to be properly evaluated in order to avoid fuel combinations with unwanted properties. Also, a comparison between their performance in fixed or fluidized bed units has not been made.

In previous work in our lab $[6,21,22]$, the thermal behaviour, the combustion efficiency, the emissions, as well as the partitioning of inorganic constituents as a function of operating conditions were investigated for similar samples to those adopted in present work. The objective of this study was to evaluate and compare the ashes produced from both fixed and fluidized bed combustion of these wastes and their mixtures. The aim was to determine the slagging and fouling propensities of these ashes, to apply simple techniques for mitigating ash-related problems, to assess their environmental impact upon disposal, as well as their potential uses with respect to legislative restrictions. As such, mineralogical, chemical, thermal and fusibility analyses were conducted to characterize the ashes, in an attempt to provide valuable information for the promotion of these wastes in fuelling small-to-medium size enterprises near wine/spirit processing industries.

\section{Experimental}

\section{Raw materials}

The raw materials of present work were vine wood collected after pruning from a vineyard in the area of Chania in the island of Crete and grape skins from a wine/spirit making factory located next to the vineyard, after extraction of juice. After air drying, the materials were ground in a cutting mill to a particle size of
$-2800+1000 \mu \mathrm{m}$ and pre-dried in the oven. Following riffling, representative samples were ground to a particle size of $-425 \mu \mathrm{m}$ and characterized by proximate analysis, ultimate analysis and calorific value according to the European standards drawn up by the Technical Committee CEN/TC335. Programmable laboratory furnaces, a CHNS Flash 2000 analyzer and an AC-350 Leco calorimeter were used for the tests. Mixtures of skins with blending ratio $30 \%$ by weight were prepared with the wood, as the latter was available in much greater quantities.

\section{Leaching tests}

Both vine wood and grape skins were washed with double distilled water, in order to reduce their problematic inorganic elements, causing slagging/fouling phenomena during combustion. The liquid-to-solid ratio was $20 \mathrm{~L} / \mathrm{kg}$ dry matter. The slurries were agitated for $2 \mathrm{~h}$ at $80{ }^{\circ} \mathrm{C}$ and then filtered in Buchner funnels. Solid materials were dried in the oven before being used in the experiments.

\section{Combustion tests}

Combustion of the fuels was carried out in a lab-scale fixed/ bubbling fluidized bed reactor, with an inner diameter of $70 \mathrm{~mm}$ and a total height of about $2 \mathrm{~m}$, as described in a previous work [6]. The tests were performed at a solid feed rate of $10 \mathrm{~g} / \mathrm{min}$ and excess air ratio 1.4. The maximum temperature recorded during combustion of vine wood was $846^{\circ} \mathrm{C}$, whereas that of grape skins was $870^{\circ} \mathrm{C}$. When the system was operated in the fluid bed mode, the minimum fluidization velocity was determined from pressure drop-velocity measurements via a cold reactor model and was found to be $0.15 \mathrm{~m} / \mathrm{s}$. Bottom ashes and fly ashes (collected from the tangential flow type cyclone) at the end of each fixed bed and fluid bed experiments, respectively, were analyzed through various techniques. Thus, the effect of raw fuels leaching process on fixed or fluidized bed system's performance, as well as on the environmental impact and potential utilization of the ash residues produced, could be determined.

Furthermore, the thermal behaviour of raw and leached materials and their blends was investigated by thermogravimetric analysis tests using a TGA/DTG Perkin Elmer analyser. Sample weight loss and rate of weight loss as functions of time or temperature were recorded continuously between 25 and $900{ }^{\circ} \mathrm{C}$. The flow rate of air was $35 \mathrm{~mL} / \mathrm{min}$ and the heating rate $10^{\circ} \mathrm{C} / \mathrm{min}$. Small particle size and mass were kept sufficiently small (below $250 \mu \mathrm{m}$ and about $20 \mathrm{mg}$, respectively) to assure kinetic regime.

\section{Ash analyses}

Mineralogical analysis of crystalline compounds was conducted with an X-ray diffractometer (XRD), model D8 Advance of Bruker AXS, with application of $\mathrm{Cu} \mathrm{K} \alpha$ radiation and nickel filter $(\mathrm{U}=35 \mathrm{kV}$, $\mathrm{I}=35 \mathrm{~mA}$ ). The XRD scans were performed between 2 and $702 \theta^{\circ}$, with increments of $0.02 \%$. A software system DIFFRAC plus Evaluation by Bruker AXS and the JCPDS database were used for data processing and identification of crystalline components. 
Differential thermal analysis experiments were carried out using the TGA/DTG analyser. The samples were heated in nitrogen in the temperature range 25 to $900{ }^{\circ} \mathrm{C}$, with a heating rate of $10^{\circ} \mathrm{C} /$ $\min$.

Fusibility analysis of ashes was conducted under oxidizing atmosphere according to European standards DDCEN/TS 153701:2006, using an Ash Fusion Determinate type 789-900, equipped with a high definition video camera. The test involved heating a sample cone of specified geometry at a rate of $5{ }^{\circ} \mathrm{C} / \mathrm{min}$ in air up to $1500{ }^{\circ} \mathrm{C}$ and recording the temperatures that characterize ash melting. These temperatures are the initial deformation temperature (IDT), the softening temperature (ST), the hemispherical temperature (HT) and the fluid temperature (FT).

Chemical analysis of ashes in major and trace elements was performed by an inductive coupled plasma mass spectrometer type ICP-MS 7500cx, coupled with an Autosampler Series 3000, both by Agilent Technologies (detection limits 0.4-34 ppb, depending on element). The samples were dissolved by a microwave-assisted digestion with $\mathrm{HNO}_{3}$ acid. The microwave digestion was carried out by using Anton Paar Multiwave 3000 oven. Phosphorous and silicon measurements were conducted using a spectrophotometer type UV-VIS Hach 4000V and an atomic absorption spectrometer (AAS) Analyst-100 of Perkin Elmer, equipped with a graphite furnace assembly (model HGA 800) and a deuterium arc lamp background correction system. For sample preparation, the procedures of $\mathrm{Li}_{2} \mathrm{~B}_{4} \mathrm{O}_{7}$ fusion or acid digestion $\left(\mathrm{HCl} / \mathrm{HF} / \mathrm{HNO}_{3}\right)$ were used, depending on the element under determination.

\section{Results and Discussion}

\section{Characterization of raw materials}

Table 1, which compares the proximate and ultimate analyses of the samples, shows that both residues were rich in volatile matter. Vine wood had low ash content, but much greater oxygen content than grape skins, resulting in a lower calorific value. Nevertheless, the gross calorific value of both fuels was comparable to the upper limit of low rank coals. Sulphur and chlorine contents, which are related to emissions, fouling and corrosion in boilers, were low, however the concentration of nitrogen in grape skins was rather high, implying increased toxic $\mathrm{NO}_{\mathrm{x}}$ emissions during combustion.

Table 1: Proximate and ultimate analyses and calorific value of the samples (\% dry weight).

\begin{tabular}{|c|c|c|c|c|c|c|c|c|c|c|}
\hline Sample & Volatile Matter & Fixed Carbon & Ash & C & $\mathbf{H}$ & $\mathbf{N}$ & $\mathbf{0}$ & S & $\mathbf{C l}$ & $\mathrm{GCV}^{\mathrm{a}}(\mathrm{MJ} / \mathbf{k g})$ \\
\hline Vine Wood (VW) & 77.1 & 19.7 & 3.2 & 46.3 & 6.3 & 0.9 & 43.4 & 0.06 & 0.01 & 18.6 \\
\hline Grape Skin (GS) & 71.7 & 13.4 & 14.9 & 49 & 6.5 & 2.5 & 26.7 & 0.4 & 0.02 & 20.7 \\
\hline
\end{tabular}

aGross calorific value.

\section{Reactivity of fuels in air}

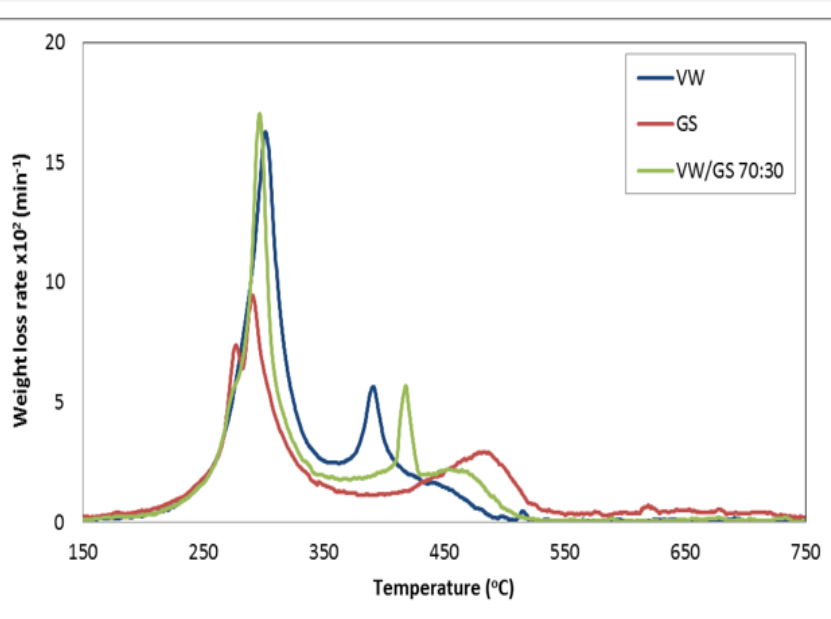

Figure 1: Weight loss rate of vine wood, grape skins and their mixture as a function of temperature.

Figure 1 compares the DTG profiles of the samples in air normalized by the initial dry mass. Two combustion stages are clearly illustrated in this figure, the first one in the range of 200$400{ }^{\circ} \mathrm{C}$ and the second one in the range $400-600{ }^{\circ} \mathrm{C}$. During the first stage the bulk of volatiles was released and burned, whereas combustion of secondary gases and char residue occurred during the second stage. Ignition occurred at nearly the same temperature for the two fuels $\left(239{ }^{\circ} \mathrm{C}\right.$ and $\left.228{ }^{\circ} \mathrm{C}\right)$, which is important for cofiring applications. This is attributed to the same $\mathrm{H} / \mathrm{C}$ ratio and the similar amount of volatiles of the samples. Vine wood consisted of a greater amount of hemi-cellulose and cellulose, which burned at a higher temperature and rate $\left(299{ }^{\circ} \mathrm{C}\right.$ and $\left.0.17 \mathrm{~min}^{-1}\right)$ than those corresponding to grape skins $\left(287^{\circ} \mathrm{C}\right.$ and $\left.0.1 \mathrm{~min}^{-1}\right)$.

One sharp and one broad smaller peak can be observed during the second temperature regime of the conversion process for vine wood and grape skins, respectively (at $387^{\circ} \mathrm{C}$ and $481{ }^{\circ} \mathrm{C}$ ), reflecting the existence of structures of different reactivity of these materials. All char material of vine wood burned up to $500{ }^{\circ} \mathrm{C}$. However, the greater yield of char of grape skins $(28.3 \%$ against $22.9 \%$ for vine wood, on dry basis, Table 1) extended its combustion up to $550{ }^{\circ} \mathrm{C}$. Thus, according to the peak height and corresponding temperature, vine wood was a more reactive fuel than grape skins. Moreover, Figure 1 shows that the burnout profile of the mixture lies between those of the individual fuels more or less in an additive manner. Consequently, no interactions are to be expected between the two fuels during co-combustion experiments.

A comparison between the deconvolution curves of the materials before and after water washing is illustrated in Figure 2. The DTG curves of vine wood show that there was a shift in the peak temperature to higher values (from $299{ }^{\circ} \mathrm{C}$ to $330{ }^{\circ} \mathrm{C}$ ) as a result of sample washing, while the combustion rate remained practically unchanged. This suggests that $\mathrm{K}, \mathrm{P}, \mathrm{S}, \mathrm{Cl}$ and especially $\mathrm{K}$, which was abundant in the raw sample as it will be presented in the sections to follow, influenced the sensitivity of the reaction in air, causing the degradation of vine wood to start at a lower temperature. On 
the other hand, the DTG curves of grape skins were also shifted to a higher temperature after the material was washed with water (from $287{ }^{\circ} \mathrm{C}$ to $320^{\circ} \mathrm{C}$ ), but the material burned within a longer time interval and with a reduced combustion rate by $40 \%$, as compared to the rate of the unwashed fuel. Therefore, it seems that minerals which were removed upon washing (Table 2), particularly potassium, catalyzed the combustion of raw grape skins fuel, enhancing the reaction rate.

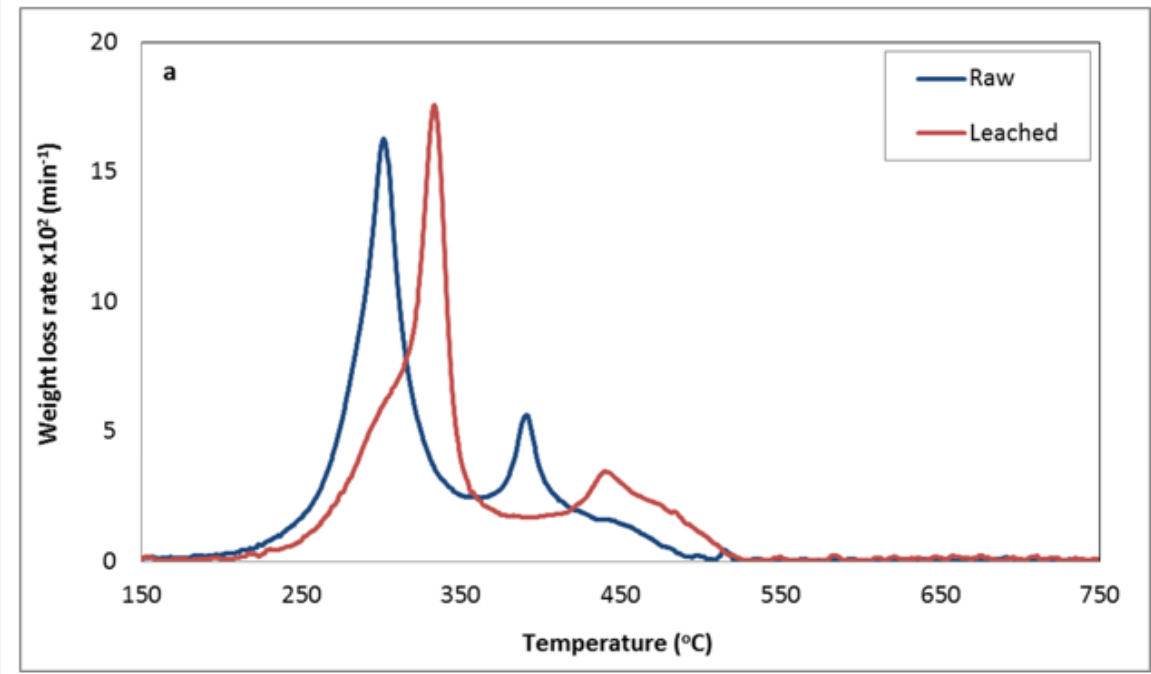

Figure 2a: Comparison between the rate of weight loss as a function of temperature of raw and leached vine wood.

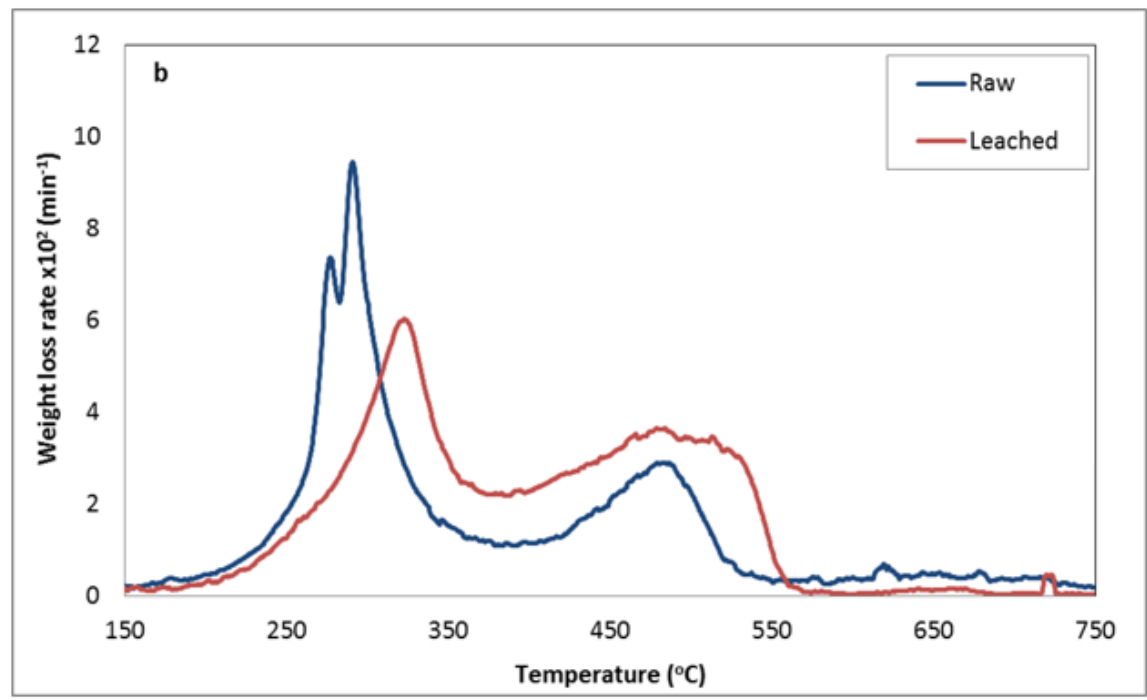

Figure $\mathbf{2 b}$ : Comparison between the rate of weight loss as a function of temperature of raw and leached grape skins.

Table 2: Mineral phases of ashes from raw and leached (I) fuels, burned in fixed/fluidized bed units.

\begin{tabular}{|c|c|c|c|c|c|c|c|c|}
\hline \multirow{3}{*}{ Mineral Phases } & \multicolumn{8}{|c|}{ Sample } \\
\hline & \multicolumn{2}{|c|}{ Fixed Bed } & \multicolumn{2}{|c|}{ Fluid Bed } & \multicolumn{2}{|c|}{ Fixed Bed } & \multicolumn{2}{|c|}{ Fluid Bed } \\
\hline & vw & $\mathrm{VW}_{1}$ & vw & vw $_{1}$ & GS & $\mathrm{GS}_{1}$ & GS & $\mathrm{GS}_{1}$ \\
\hline Quartz $\mathrm{SiO}_{2}$ & & & + & + & + & ++ & + & ++ \\
\hline Calcite $\mathrm{CaCO}_{3}$ & ++ & +++ & ++ & +++ & +++ & +++ & ++ & ++ \\
\hline Anhydrite $\mathrm{CaSO}_{4}$ & & & & & + & + & + & + \\
\hline Albite $(\mathrm{Na}, \mathrm{Ca}) \mathrm{Al}(\mathrm{AlSi})_{3} \mathrm{O}_{8}$ & + & + & +++ & ++ & & & +++ & ++ \\
\hline Muscovite $\mathrm{KAl}_{2}\left(\mathrm{Si}_{3} \mathrm{AlO}_{10}\right)(\mathrm{OH})_{2}$ & & & + & + & & & + & + \\
\hline Microcline $\mathrm{KAISi}_{3} \mathrm{O}_{8}$ & & & & & + & + & + & + \\
\hline Dolomite CaMg $\left(\mathrm{CO}_{3}\right)_{2}$ & + & + & & & + & + & & \\
\hline Magnesite $\mathrm{MgCO}_{3}$ & & & & & + & & & \\
\hline Fairchildite $\mathrm{K}_{2} \mathrm{Ca}\left(\mathrm{CO}_{3}\right)_{2}$ & ++ & & + & & ++ & & + & \\
\hline Arcanite $\mathrm{K}_{2} \mathrm{SO}_{4}$ & + & & + & & + & + & ++ & + \\
\hline
\end{tabular}




\begin{tabular}{|c|c|c|c|c|c|c|c|}
\hline Halite potassian $\mathrm{K}_{0.4} \mathrm{Na}_{0.6} \mathrm{Cl}$ & + & & & & + & & \\
\hline Hematite $\mathrm{Fe}_{2} \mathrm{O}_{3}$ & & & & & + & + & + \\
\hline Sylvite $\mathrm{KCl}$ & & & & & + & + & + \\
\hline Periclase $\mathrm{MgO}$ & + & + & + & + & & & + \\
\hline Hydroxyapatite $\left.\left.\mathrm{Ca}_{5} \mathrm{PO}_{4}\right)_{3} \mathrm{OH}\right)$ & ++ & + & + & + & + & + & + \\
\hline Struvite $\mathrm{MgNH}_{4} \mathrm{PO}_{4}\left(\mathrm{H}_{2} \mathrm{O}_{6}\right.$ & & & & & + & & + \\
\hline
\end{tabular}

+++: high intensity ++: medium intensity +: low intensity.

\section{Mineral phases in ashes}

Table 2 lists the crystalline mineral phases of fixed bed and fluid bed ashes produced from the combustion of raw and leached fuels, as these were identified by the XRD.

Both ashes of vine wood were dominated by Ca-based minerals in the form of calcite, hydroxyapatite and fairchildite, due to the high content of calcium naturally occurring in wood. A small amount of dolomite was also present in the fixed bed ash. Periclase was probably formed by combustion of magnesia, or partial decomposition of dolomite at temperatures higher than $800{ }^{\circ} \mathrm{C}$. Potassium, which was found in higher proportions in the XRD spectra of fixed bed ash, was present in the forms of arcanite, fairchildite and halite potassium. As can be observed, carbonates, sulphates and phosphates were partly vaporized during fluidized bed combustion and condensed on cyclone ash. The minerals albite, muscovite and quartz detected in vine wood fly ash were remnants of elutriated inert bed material in the cyclone.

Fixed bed and fly ashes of grape skins, besides the Ca-based minerals also identified in vine wood ashes, contained a considerable amount of anhydrite, which was formed by dehydration of gypsum $\left(\mathrm{CaSO}_{4} \cdot 2 \mathrm{H}_{2} \mathrm{O} \rightarrow \mathrm{CaSO}_{4}+\mathrm{H}_{2} \mathrm{O}\right)$ and/or reactions between calcium and sulphur liberated during combustion $\left(\mathrm{CaO}+\mathrm{SO}_{2}+0.5 \mathrm{O}_{2} \rightarrow\right.$ $\mathrm{CaSO}_{4}$ ). Also, a small amount of hematite was detected in both ashes, which could have been produced from oxidation of organic iron or siderite during the combustion process $\left(2 \mathrm{FeCO}_{3}+0.5 \mathrm{O}_{2} \rightarrow\right.$ $\mathrm{Fe}_{2} \mathrm{O}_{3}+\mathrm{CO}_{2}$ ). On the other hand, magnesium was present only in fixed bed as magnesite, dolomite and struvite, revealing that these minerals were concentrated in the bottom ash of the fluid bed configuration. Silicates, such as albite and muscovite in fly ash, were the constituents of the inert bed material elutriated in the cyclone, while the small contribution of microcline in both ashes could be attributed to reactions of arcanite or sylvite with quartz and alumina $\left(\mathrm{K}_{2} \mathrm{SO}_{4}+\mathrm{Al}_{2} \mathrm{O}_{3} \cdot \mathrm{SiO}_{2}+5 \mathrm{SiO}_{2} \rightarrow 2 \mathrm{KAlSi}_{3} \mathrm{O}_{8}+\mathrm{SO}_{3}\right.$ or $2 \mathrm{KCl}+\mathrm{Al}_{2} \mathrm{O}_{3}$. $\mathrm{SiO}_{2}+5 \mathrm{SiO}_{2}+\mathrm{H}_{2} \mathrm{O} \rightarrow 2 \mathrm{KAlSi}_{3} \mathrm{O}_{8}+2 \mathrm{HCl}$ ) [11]. Finally, grape skins ashes were enriched in potassium, which was incorporated in arcanite, fairchildite, sylvite and halite potassium. These minerals, apart from halite potassium, were partly captured in the cyclone during the fluidized bed tests. Among phosphates, only hydroxyapatite was distributed between fly and bottom ash of the fluid bed system. The mineral phases of the ashes produced during the combustion of vine wood and grape skins mixtures, being identical with those identified in individual fuels, are not presented in Table 2 for economy reasons.
The effect of the water leaching process applied to the raw materials studied, on the mineralogical composition of ashes produced from either fixed or fluidized bed combustion experiments, is also indicated in Table 2. As can be clearly seen, carbonates, chlorides and phosphates, such as fairchildite, magnesite, halite potassium and struvite were easily dissolved in water by leaching, whereas sylvite among chlorides and hydroxyapatite among phosphates were partly soluble. Moreover, during vine wood leaching, arcanite was removed and retained in water, however during grape skins leaching it was partly dissolved. $\mathrm{Si}$, Fe and Al were associated with stable minerals in the ashes, such as quartz, microcline and hematite.

\section{Thermal behaviour of ashes}

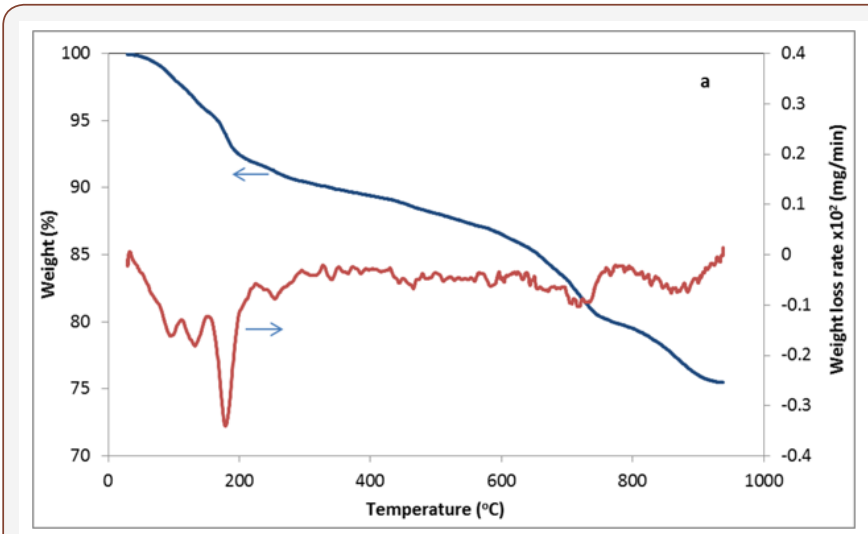

Figure 3a: Weight loss and rate of weight loss as a function of temperature of grape skins ash produced from combustion of raw fuel in the fixed bed unit.

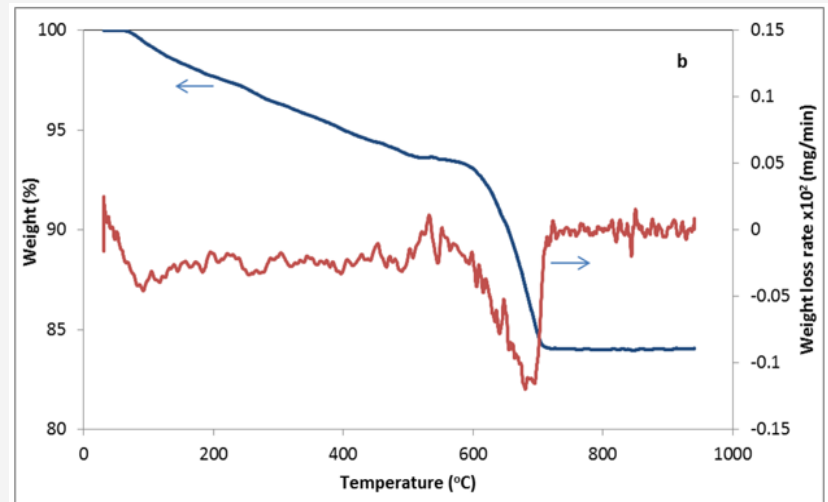

Figure 3b: Weight loss and rate of weight loss as a function of temperature of grape skins ash produced from combustion of leached fuel in the fixed bed unit.

Representative TGA/DTG graphs of the ashes studied are illustrated in Figure 3. According to these profiles, the main 
weight loss occurred in the temperature range $670-900{ }^{\circ} \mathrm{C}$ for both ashes of raw and leached grape skins material and the peaks were registered at $715{ }^{\circ} \mathrm{C}, 866^{\circ} \mathrm{C}$ and $695^{\circ} \mathrm{C}$, respectively. These correspond to the decomposition of carbonate minerals calcite, dolomite and magnesite. The peak observed at $180^{\circ} \mathrm{C}$ is attributed to the decomposition of basanite mineral, which was transformed in anhydrite. The total mass loss was $24 \%$ and $15 \%$ for raw and leached fuels. Any peaks related to the dissociation of arcanite, sylvite, anhydrite or fairchildite (for raw material) could not be recorded, because these processes occur at temperatures higher than $900{ }^{\circ} \mathrm{C}$ [23]. All samples presented considerable weight loss in the same temperature range.

\section{Fusibility behaviour of ashes}

The characteristic fusion temperatures of the ashes of raw fuels and their mixture, which were determined by the heating microscope, are represented in Table 3. These temperatures are Table 3: Fusibility analysis of ashes from raw and leached (I) fuels and their blend.

\begin{tabular}{|c|c|c|c|c|}
\hline Sample & $\begin{array}{l}\text { Initial Deformation Temperature } \\
\text { (IDT) }\left({ }^{\circ} \mathrm{C}\right)\end{array}$ & $\begin{array}{l}\text { Softening Temperature } \\
\text { (ST) }\left({ }^{\circ} \mathrm{C}\right)\end{array}$ & $\begin{array}{c}\text { Hemispherical Temperature } \\
\text { (HT) }\left({ }^{\circ} \mathrm{C}\right)\end{array}$ & $\begin{array}{l}\text { Fluid Temperature } \\
\text { (FT) }\left({ }^{\circ} \mathrm{C}\right)\end{array}$ \\
\hline VW & 1237 & 1475 & 1493 & 1516 \\
\hline GS & 1080 & 1215 & 1396 & 1501 \\
\hline VW/GS 70:30 & 1151 & 1357 & 1452 & 1503 \\
\hline VWl & 1242 & 1489 & 1500 & 1524 \\
\hline GSl & 1237 & 1445 & 1526 & 1541 \\
\hline VWl/GSl 70:30 & 1196 & 1325 & 1482 & 1512 \\
\hline
\end{tabular}

When raw materials were leached with water, the results clearly indicate that all characteristic fusion temperatures of grape skins ash were significantly increased, IDT by $157^{\circ} \mathrm{C}$, ST by $230^{\circ} \mathrm{C}$, HT by $130{ }^{\circ} \mathrm{C}$ and FT by $40{ }^{\circ} \mathrm{C}$. This behavior is explained by the dissolution of fairchildite, halite potassian, struvite and magnesite minerals in water and consequently an ash enriched in silicon and calcium phases with higher melting points after the leaching process. On the other hand, the melting behavior of vine wood ash was not greatly affected by water washing, due to its lower alkaline nature, as compared to grape skins ash. Furthermore, as concerns the blend of these fuels, it can be noticed that fusion temperatures varied between those of the individual components, but not in proportion to each material's content in the mixture. Hence, there is always a need for experimental tests when mixtures of biomass fuels are used, before drawing conclusions about their behavior on systems performance or certain applications, in order to avoid fuel combinations with unwanted properties.

Present findings are in agreement with fusibility data of previous studies for similar agricultural residues [9, 10, 13, 24]. Also, they suggest that simple and fast techniques, such as water leaching, could greatly reduce ash deposition phenomena in power systems and thus the overall cost. important for predicting the slagging and fouling tendencies of the fuels in boilers and are directly related to ash chemistry and mineralogy. As can be observed, grape skins started to deform and soften at a much lower temperature than vine wood $\left(140{ }^{\circ} \mathrm{C}\right.$ and $250{ }^{\circ} \mathrm{C}$ lower, respectively), as it contained less calcium and phosphorous, whereas more potassium than vine wood present in the fusible forms of fairchildite, arcanite, sylvite and halite potassium. An ash deformation temperature of $1080{ }^{\circ} \mathrm{C}$ could create deposition problems in most combustion processes, except fluidized bed systems operating around $800^{\circ} \mathrm{C}$. This was confirmed by the present experiments conducted in the fluid bed configuration, where no signs of ash deposition or bed agglomeration were noticed. Nevertheless, Table 3 shows that the fluid temperatures of both ashes exceeded $1500^{\circ} \mathrm{C}$. However, the very small temperature difference between the ST and FT of vine wood ash $\left(41^{\circ} \mathrm{C}\right)$ implies a higher fouling rate inside the boilers.

\section{Major and trace chemical species in ashes}

In Figure $4 \mathrm{a}$, the concentrations of major elements in vine wood and grape skins ashes obtained from combustion of these materials in the fixed bed configuration, are compared. Both ashes were enriched in $\mathrm{Ca}, \mathrm{K}, \mathrm{P}, \mathrm{Si}$ and $\mathrm{Mg}$, most of which are known to be plant nutrients and soil improvement agents [11]. The greater amount of $\mathrm{K}$ in grape skins ash and that of $\mathrm{P}$ in vine wood ash are in accordance with the presence of arcanite, fairchildite, sylvite, halite potassium and hydroxyapatite, respectively, identified through XRD analysis. The higher percentage of $\mathrm{Si}$ in grape skins ash was attributed to quartz and microcline, as previously shown, while $\mathrm{Si}$ in vine wood ash was incorporated in a smaller amount in mineral albite.

The chemical analysis of fly ashes, produced from the combustion of the fuels in the fluid bed system, are represented in Figure $4 \mathrm{~b}$. The elevated concentrations of $\mathrm{Si}, \mathrm{Al}$ and $\mathrm{Na}$ observed in this figure are consistent with the composition of the inert bed material used in the fluid bed system, which was elutriated in the cyclone (Table 2). On the other hand, the increased proportions of $\mathrm{K}$ and $\mathrm{P}$ in the fly ash of grape skins can be explained by the higher contents of these elements originally found in this sample [21], as well as the increased entrainment with flue gases of sulphate, chloride and hydroxide species such as arcanite, sylvite and hydroxyapatite with respect to vine wood fly ash. 


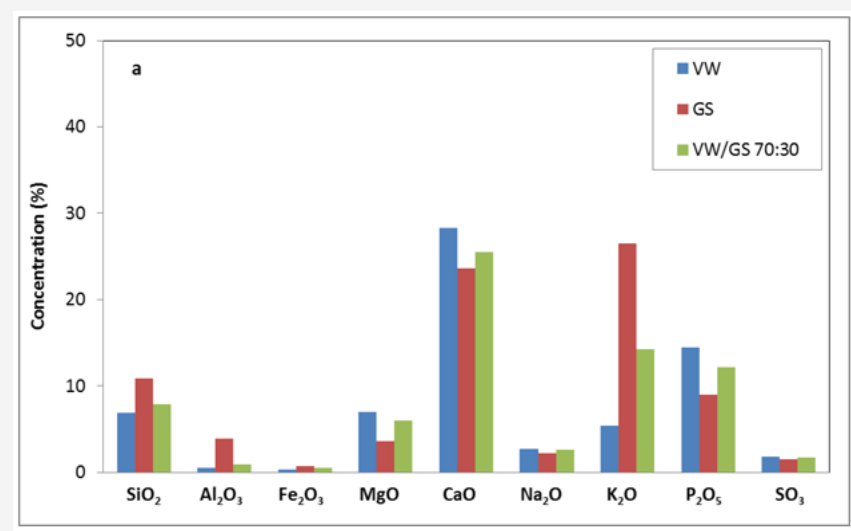

Figure 4a: Major elements in ashes produced from combustion of fuels and their mixture in fixed bed unit.

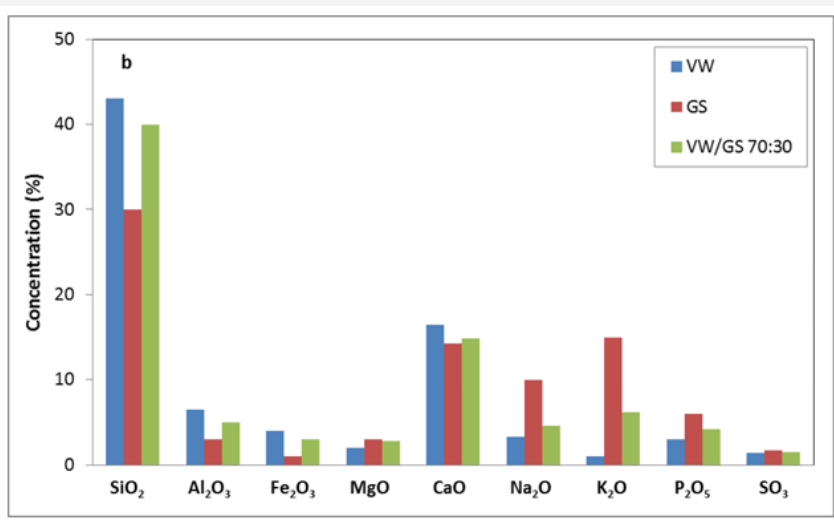

Figure 4b: Major elements in ashes produced from combustion of fuels and their mixture in fluid bed unit.

Trace element concentrations in fixed bed ashes, as determined by the ICP-MS analysis, are illustrated in Figure $5 \mathrm{a}$, while in fly ashes in Figure 5b. Heavy metal values of toxic elements As, $\mathrm{Hg}$, Cd and Co, ranging between $<0.03 \mathrm{mg} / \mathrm{kg}$ and $2.6 \mathrm{mg} / \mathrm{kg}$, were omitted from the graphs. The level of $\mathrm{Pb}$ (3.8-15.9 mg/kg) was generally lower to that reported in literature for similar fuels [8,25]. Figure 5a shows that grape skins ash contained higher amounts of $\mathrm{Cr}$, $\mathrm{Ni}$ and $\mathrm{Cu}$ than vine wood ash, which was a lot richer in $\mathrm{Zn}$. However, a comparison with the data of Figure 5b indicates that trace elements (except $\mathrm{Cr}$ ) showed less preference for the cyclone ash during fluidized bed experiments and this is a consequence of the ash chemistry and process conditions. In the case of vine wood, $\mathrm{Ni}, \mathrm{Cu}$ and $\mathrm{Zn}$ were mostly concentrated in the bottom ash of the fluid bed system. Nevertheless, in the case of grape skins, $\mathrm{Cu}$ and $\mathrm{Zn}$ presented a moderate volatility and were partially retained in the fly ash, due to their possible association with phosphates or carbonates, as those identified in XRD spectra [17]. The unexpectedly high values of $\mathrm{Cr}$ in both fly ashes were due to contamination of these materials with stainless steel attrite in the cyclone, as also confirmed by other studies $[25,26]$. All current heavy metal values, of either fixed or fluid bed ashes, were found below the upper limit for disposal in landfills, according to EU directives [27].

Furthermore, blending vine wood, which is the most abundant residue of vineyards, with grape skins at percentages up to $30 \%$, aiming to increase supply options in case of their thermal exploitation, resulted in ash compositions intermediate to each mixture component, as can be seen from Figures $4 \& 5$. The ash of the mixtures was enriched in nutrients $\mathrm{K}$ and $\mathrm{Cu}$, as compared to the ash of vine wood. The present results are consistent with literature data reporting chemical analyses of agricultural residue ashes [17,25,28].

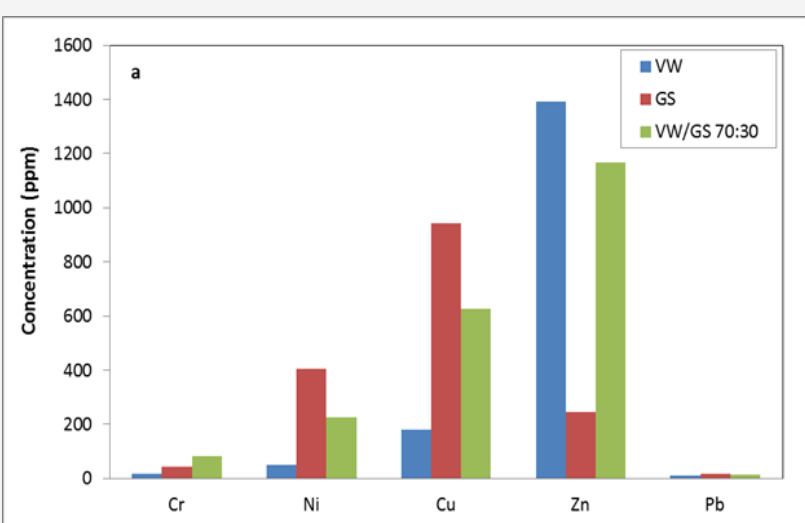

Figure 5a: Trace elements in ashes produced from combustion of fuels and their mixture in fixed bed unit.

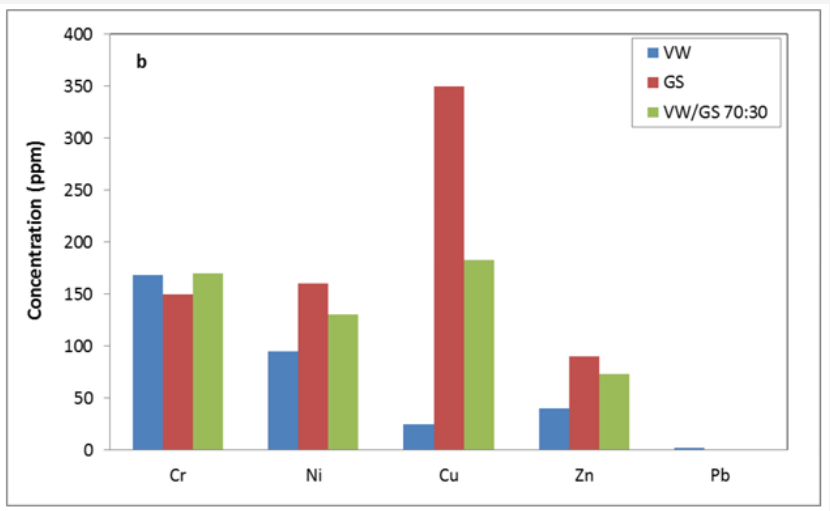

Figure 5b: Trace elements in ashes produced from combustion of fuels and their mixture in fluid bed unit.

In order to investigate the influence of water leaching applied to the raw materials studied, their composition in inorganic elements was determined before and after this process, by keeping the ashing temperature at $550{ }^{\circ} \mathrm{C}$, so that the mineral phases would remain unaltered [21]. The results showed that problematic elements $\mathrm{K}, \mathrm{Na}, \mathrm{P}, \mathrm{S}$ and $\mathrm{Cl}$, were significantly reduced upon leaching, in accordance to the solubility of the original minerals in which these elements were incorporated. As previously discussed, some carbonates (fairchildite, magnesite), phosphates (struvite), sulphates (arcanite) and chlorides (halite potassium) presented increased leachability. Thus, $\mathrm{K}_{2} \mathrm{O}$ and $\mathrm{Na}_{2} \mathrm{O}$ were depleted up to $81 \%, \mathrm{P}_{2} \mathrm{O}_{5}$ up to $77 \%, \mathrm{SO}_{3}$ up to $98 \%$ and $\mathrm{Cl}$ up to $99 \%$. On the other hand, trace metals were not released in the extracts, suggesting that they were adsorbed on stable minerals insoluble in water. These findings were reflected in the compositions of ashes of both fuels, which were produced from the combustion of unbleached and leached materials in the fixed and fluid bed configurations. The principal effects are demonstrated in Figure 6 for the variations in $\mathrm{K}$ and $\mathrm{P}$ concentrations and in Table 4 for the variations in trace element concentrations with leaching. According to these results, it can be concluded that leaching of fuel mixtures will also mitigate 
to a great extent slagging, fouling, corrosion and environmental problems caused by the presence of alkali, sulphur and chlorine. Despite these promising results, it must be mentioned that further leachability tests are required, before using these agricultural wastes for energy production in higher scale units.

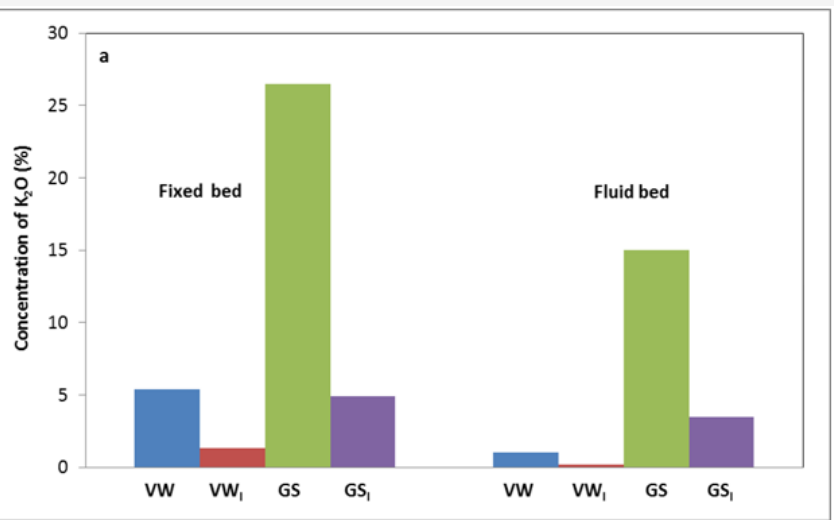

Figure 6a: Concentration of $\mathrm{K}_{2} \mathrm{O}$ in ashes produced from combustion of raw and leached fuels in fixed and fluid bed units.

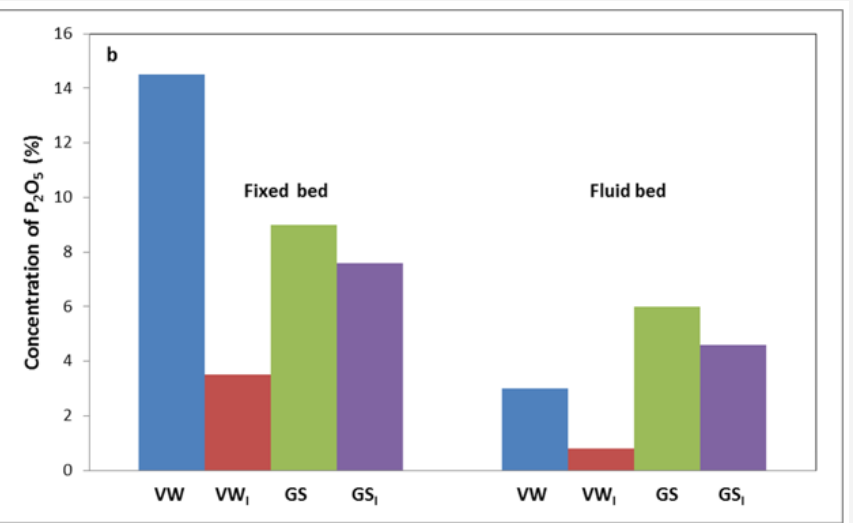

Figure 6b: Concentration of $\mathrm{P}_{2} \mathrm{O}_{5}$ in ashes produced from combustion of raw and leached fuels in fixed and fluid bed units.

Table 4: Trace element concentrations of ashes from raw and leached (I) fuels, burned in fixed/fluidized bed units.

\begin{tabular}{|c|c|c|c|c|c|}
\hline \multirow{2}{*}{ Sample } & \multicolumn{5}{|c|}{ Trace Element Concentration (mg/kg) } \\
\cline { 2 - 6 } & Cr & Ni & Cu & Zn & Pb \\
\hline \multicolumn{7}{|c|}{ Fixed Bed } \\
\hline VW & 15 & 48 & 181 & 1390 & 12 \\
\hline VW $_{1}$ & 46 & 176 & 208 & 2070 & 17 \\
\hline GS & 43 & 405 & 942 & 245 & 16 \\
\hline GS $_{1}$ & 65 & 1170 & 1650 & 502 & 29 \\
\hline \multicolumn{7}{|c|}{ Fluid Bed } \\
\hline VW $^{2}$ & 168 & 95 & 25 & 40 & 1.7 \\
\hline VW $_{1}$ & 197 & 246 & 28 & 61 & 2.1 \\
\hline GS & 150 & 160 & 350 & 90 & 0.2 \\
\hline GS $_{1}$ & 208 & 348 & 576 & 150 & 0.4 \\
\hline
\end{tabular}

*Values in parenthesis represent cumulative mass leached (\%).

\section{Potential uses of ashes}

Relevant to the valorization of the ash materials investigated in this study, the results have shown that the calcareous content of these ashes was quite small for hydraulic properties to develop and their low $\mathrm{SiO}_{2}$ content is characteristic of low pozzolanic materials. The elevated amount of $\mathrm{SiO}_{2}$ in fly ashes was a result of the experimental conditions and not of the inherent composition of ashes, as it was attributed to some inert bed material elutriated in the cyclone. The absence of aluminosilicate compounds could not render these ashes, as received, suitable for cement industry applications. They could be used though for road construction, or as secondary building materials in the manufacture of bricks, tiles etc. [29].

The increased concentrations in nutrients such as $\mathrm{Ca}, \mathrm{K}, \mathrm{P}, \mathrm{Cu}$ and $\mathrm{Zn}$, the low content of toxic trace elements associated with stable mineral phases and the alkaline nature of either fixed or fluid bed ashes, produced from combustion of unbleached grape skins, could allow their use for soil amelioration, liming, or possibly fertilization. Blending with other organic or inorganic by-products would enhance their performance for such applications.

\section{Conclusion}

Vine wood and grape skins were characterized by high volatile, whereas low sulphur and chlorine contents. The amount of ash and nitrogen in vine wood were rather high. Ignition occurred at nearly the same temperature for the two fuels, the co-combustion of which showed an additive behaviour.

The ashes produced from combustion of these wastes, in fixed and fluidized bed units, were rich in $\mathrm{Ca}, \mathrm{K}, \mathrm{P}$ and $\mathrm{Si}$, associated principally with calcite, fairchildite, hydroxyapatite and albite minerals, identified through the XRD analysis. The increased proportions of $\mathrm{K}$ and $\mathrm{P}$ in the fly ash of grape skins were attributed to partial entrainment of arcanite, sylvite and hydroxyapatite minerals. Vine wood ashes were enriched in $\mathrm{Zn}$, while grape skins ashes in $\mathrm{Cu}$ and $\mathrm{Ni}$, among trace elements. Heavy metals showed less preference for fly ashes and all values were below the upper limit for disposal in landfills. Fusibility analysis showed that grape skins ash started to deform and soften at a much lower temperature than vine wood, due to its higher concentration in $\mathrm{K}$ present in fusible minerals. However, for both wastes or their mixture, no deposition problems are anticipated in systems operating below $1000{ }^{\circ} \mathrm{C}$. The fusibility behavior of the blend showed some synergy.

When raw materials were leached with water, problematic elements in ashes, in terms of slagging/fouling or corrosion phenomena, were greatly reduced, due to dissolution of some carbonates, phosphates, sulphates and chlorides in ashes. Trace metals were not released in the extracts. Potassium, although found to catalyze the combustion of grape skins, by its removal increased significantly the fusion temperatures and hence lowered the slagging/fouling tendency of ashes.

Fixed bed or fly ashes of the materials studied could be used as secondary building materials, or for road construction. Those of grape skins could also be used for soil amendment.

\section{Acknowledgement}

The authors kindly thank the laboratories of Hydrogeochemical Engineering and Soil Remediation and Inorganic and Organic Geochemistry for the chemical analysis of the ashes. 


\section{Conflict of Interest}

No conflict of interest.

\section{References}

1. Directive 2009/28/EC of the European Parliament and of the Council of 23April 2009 on the promotion of the use of energy from renewable sources and amending and subsequently repealing Directives 2001/77/ EC and 2003/30/EC Off J. 05/06/2009; 40: 0016-62.

2. Vamvuka D (2009) Biomass, bioenergy and the environment. Tziolas Publications, Salonica, Greece.

3. Vamvuka D, Tsoutsos T (2002) Energy exploitation of agricultural residues in Crete. Energy Exploration and Exploitation 20(1): 113-121.

4. Van Caneghem J, Brems A, Lievens P, Block C, Billen P, et al. (2012) Fluidized bed waste incinerators: Design, operational and environmental issues. Progress in Energy and Combustion Science 38(4): 551-582.

5. Pecora AAB, Avila I, Lira CS, Cruz G, Crnkovic PM (2014) Prediction of the combustion process in fluidized bed based on physical-chemical properties of biomass particles and their hydrodynamic behaviors. Fuel Processing Technology 124: 188-197.

6. Vamvuka D, Galetakis M, Merkoulidi G (2017) Investigation of the combustion performance of residues from vineyards and processing industry via fluidized bed experiments, factorial design and modeling. Combustion Science and Technology 189(5): 890-907.

7. Vamvuka D, Zografos D, Alevizos G (2008) Control methods for mitigating biomass ash-related problems in fluidized beds. Bioresource Technology 99(9): 3534-3544.

8. Vassilev S, Baxter D, Vassileva C (2014) An overview of the behaviour of biomass during combustion: Part II. Ash fusion and ash formation mechanisms of biomass types. Fuel 117(Part A): 152-183.

9. Garcia Maraver A, Mata Sanchez J, Carpio M, Perez Jimenez J (2017) Critical review of predictive coefficients for biomass ash deposition tendency. J. of the Energy Institute 90(2): 214-228.

10. Magdziarz A, Dalai A, Kozinski J (2016) Chemical composition, character and reactivity of renewable fuel ashes. Fuel 176: 135-145

11. Steenari BM, Lindqvist O (1997) Stabilisation of biofuel ashs for recycling to forest soil. Biomass and Bioenergy 13(1-2): 39-50.

12. Dahl O, Nurmesniemi H, Pöykiö R, Watkins G (2009) Comparison of the characteristics of bottom ash and fly ash from a medium-size (32MW) municipal district heating plant incinerating forest residues and peat in a fluidized-bed boiler. Fuel Processing Technology 90(7-8): 871-878.

13. Yu C, Thy P, Wang L, SN Anderson, Jean Vandergheynst, et al. (2014) Influence of leaching pretreatment on fuel properties of biomass. Fuel Processing Technology 128: 43-53.
14. Garcia R, Pizarro C, Alvarez A, Lavin AG, Bueno JL (2015) Study of biomass combustion wastes. Fuel 148: 152-159.

15. Rizvi T, Xing P, Pourkashanian M, Darvell L, Jones J, et al. (2015) Prediction of biomass ash fusion behaviour by the use of detailed characterization methods coupled with thermodynamic analysis. Fuel 141: 275-284.

16. Wang Y, Shao Y, Matovic MD, Whalen J (2015) Exploring switchgrass and hardwood combustion on excess air and ash fouling/slagging potential: Laboratory combustion test and thermogravimetric kinetic analysis. Energy Conversion and Management 97: 409-419.

17. Vamvuka D (2009) Comparative fixed/fluidized bed experiments for the thermal behaviour and environmental impact of olive kernel ash. Renewable Energy 34(1): 158-164.

18. Saqib N, Backstrom M (2015) Distribution and leaching characteristics of trace elements in ashes as a function of different waste fuels and incineration technologies. J of Environmental Sciences 36: 9-21.

19. Siddique R (2012) Utilization of wood ash in concrete manufacturing Resources. Conservation and Recycling 67: 27-33.

20. Ram LC, Masto RE (2014) Fly ash for soil amelioration: A review on the influence of ash blending with inorganic and organic amendments. Earth-Science Reviews 128: 52-74.

21. Sfakiotakis S (2016) Study on the exploitation of agricultural, urban and industrial wastes of Crete for power production-Thermal and kinetic analyses. PhD dissertation, Technical University of Crete, Chania, Greece.

22. Vamvuka D, Trikouvertis M, Pentari D, Alevizos G, Stratakis A (2017) Characterization and evaluation of fly and bottom ashes from combustion of residues from vineyards and processing industry. J. of the Institute of Energy 90(4): 574-587.

23. Du S, Yang H, Qian K, Wang X, Chen H (2014) Fusion and transformation properties of the inorganic components in biomass ash. Fuel 117: 12811287.

24. Dunnu G, Maier J, Scheffknecht G (2010) Ash fusibility and compositional data of solid recovered fuels. Fuel 89: 1534-1540.

25. Li L, Yu C, Bai J, Wang Q, Luo Z (2012) Heavy metal characterization of circulating fluidized bed derived biomass ash. Journal of Hazardous Materials 233-234: 41-47.

26. Goodarzi F (2006) Morphology and chemistry of fine particles emitted from a Canadian coal-fired power plant. Fuel 85(3): 273-280.

27. EU Directive 86/278/EEC (1986) Protection of the environment and in particular of the soil, when sewage sludge is used in agriculture.

28. Modolo RCE, Tarelho LAC, Teixeira ER, Ferreira VM, Labrincha JA (2014) Treatment and use of bottom bed waste in biomass fluidized bed combustors. Fuel Processing Technology 125: 170-181.

29. Ahmaruzzaman M (2010) A review on the utilization of fly ash. Progress in Energy and Combustion Science 36(3): 327-363. 